\title{
Recent Studies of Image and Soft Computing Techniques for Plant Disease Recognition and Classification
}

\author{
Hiteshwari Sabrol \\ (Ph.D Research Scholar) \\ Department of Computer Science and Applications, \\ Panjab University, Chandigarh 160014 India.
}

\author{
Satish Kumar \\ Department of Computer Applications, P.U. SSG \\ Regional Centre, Hoshiarpur 146023 India. \\ (Panjab University, Chandigarh)
}

\begin{abstract}
The plant diseases are a normal part of nature but can cause significant economic, social and ecologic loss globally. It's difficult to monitor continuously plant health and detection of diseases. The paper presents a survey of recent studies on the area of plant disease recognition and classification from digital images using image processing and soft computing techniques. The main aim of the paper is to focus on the area of plant pathology recognition and classification only. The paper is omitting the disease severity quantification. Although the paper, considering the images of symptoms presents on plant leaves and stems only for limiting the survey. Each considered paper in the review, representing the comprehensive details of the technical implementation of an algorithm. The algorithm begins with digital image acquisition of infected and non-infected plants; perform image preprocessing, differentiate disease infected region from a non-infected region using segmentation, extract features from segmented images for recognition and classification. This survey expected to useful for researchers from plant pathology and pattern recognition field.
\end{abstract}

\section{Categories and Subject Descriptors}

I.4 and I.5 [Image processing and computer vision, Pattern Recognition]: Image Acquisition, Segmentation, Feature Extraction, Recognition and Classification

\section{Keywords}

Plant diseases, image processing, support vector machine (SVM), neural network.

\section{INTRODUCTION}

The interrogators, especially from developing countries now a day are taking an interest in doing their research in the field of plant disease detection. The reason is that the economic growth of the majority of these countries depends upon the agriculture. Plant disease detection at early stages is another good area of research. There are several pathologies like fungal, bacterial, and viral, etc. that affects plants and has the potential to cause economic, social and ecologic loss worldwide. So there is a dire need for developing the accurate methods to detect plant diseases timely. Various techniques have been used in past to detect and prevent the diseases in plants to minimize any of the losses in the crop. The diseases of the plants can be in earlier or later stage. In plants where diseases occur in early stage contain no visual symptoms, and human eyes are not able to guess the presence of any kinds of pathology affecting the plant. In such cases, the powerful microscopes are needed. [Sankaran et al. 2010] ${ }^{[26]}$ describes the two approaches to detect diseases in such cases. The approaches are spectroscopic and imaging techniques and volatile organic metabolites as possible biomarkers. One more approach, based on remote sensing, is also used in the same context on multi and the hyperspectral image captured data. This approach not considered in this paper. The presence of a disease on the plant somehow guessed by its visual symptoms that can be observed by the human eye. But guessing the disease severity in terms of quantification is still not an easy task. The more information related to disease severity quantification can be found in [Garcia et al. 2013] ${ }^{[8]}$. Moreover, monitoring the large area of the field for detection of diseases is also challenging the task. Therefore, the techniques based on the analysis of the digital images using pattern recognition and soft computing techniques can be helpful for providing the solution to the problem.

\section{LITERATURE REVIEW}

Plant pathology may present in the different parts of a plant like roots, seedling, stem, leaves, and fruits. In this section, we concentrate on the pathology present in plant leaves and stems. The various subsections describe the proposed technical solutions and their implementation as provided by prominent authors. The majority of paper covered under this section has adopted a common way of image acquisition, preprocessing, segmentation, feature extraction followed by different recognition and classification techniques.

Some of the described methods required control laboratory environment under which they operate.

Recognition of patterns is to identify and extract similar characteristics describing the entities present in the different patterns. To categorized any pattern in a new environment that belongs to one of the pattern classes. [Jasmin et al. $2013]^{[14]}$ Pattern is the representation of any element of a group describing a pattern class. A group of patterns belongs to distinct classes then it is considered to different patterns to which classes they are belonging by using automatic devices. In the field of plant pathology, the key issue is to detect the influenced area due to disease and identify the disease based on its pattern available on images. Also, the symptoms of infected plants can be helpful to diagnose the disease accurately as an additional feature to pattern recognition technique. The disease pattern features and tentative symptoms used as input data to detect and identify the disease. Below given three steps are used in pattern recognition approach: 
Data Representation: - It describes the property of the pattern on the basis of which the disease recognized. The plant disease symptoms and be the additional description for recognition or final confirmation.

Classification: - It is used to categorize the pattern into different classes to ascertain to which class the pattern belongs to (plant disease symptoms pattern classes).

Prototyping: - Developing the models or prototypes to classify and recognize the patterns in different classes. (Automatic plant disease recognition system or model or prototype)

Classification [Du et al. 2004] $]^{[7]}$ categorizes different patterns by classifying them according the classes they belonged. It involved that features of known patterns must compare with unknown patterns or another known criterion. These patterns are determining that whether unknown patterns are falling into a particular category or not. The classification is the recognition of pattern classes. In plant pathology, each disease represents the pattern class. A wide variety of approaches has used for the plant disease recognition and classification in the past.

Most of the classification methods include segmentation then features extraction that fed into a classifier as an input for classification. In some cases, instead of applying a complete classification process, we need to perform a partial classification. It happens in the situation when a disease has to identify among the several pathologies and as a result of this only candidate region of interest (ROI) is identified for the disease of interest only. The recognition of one or more diseases in different environment conditions with distinct visual symptoms among a number of pathologies is a challenging task.

The studies included in the paper covering almost the common steps given in Figure 1 for plant disease recognition and classification:

1. Image Acquisition: Acquired disease infected and noninfected plant images using digital devices.

2. Image preprocessing: Image Smoothing, Enhancement, and Filtering, etc.

3. Color space conversion: RGB to $\mathrm{HSV}$, HSI, and $\mathrm{YCbCr}$, etc.

4. Image segmentation: Color, Thresholding, and Otsu method, etc.

5. Feature Extraction: Color, Shape and Texture and the combination of color texture, etc.

6. Recognition and Classification: Feature Analysis, Neural Network, Support Vector Machine and Fuzzy and Rule-Based Classification.

The various methods found in the literature represented in the subsection categorization and each category describes the detailed description of technique used by the authors in their corresponding papers are following:

1. Feature Analysis (Table 1)

2. Neural Networks (Table 2)

3. Support Vector Machine (Table 3)

4. Fuzzy and Rule Based Classification (Table 4)

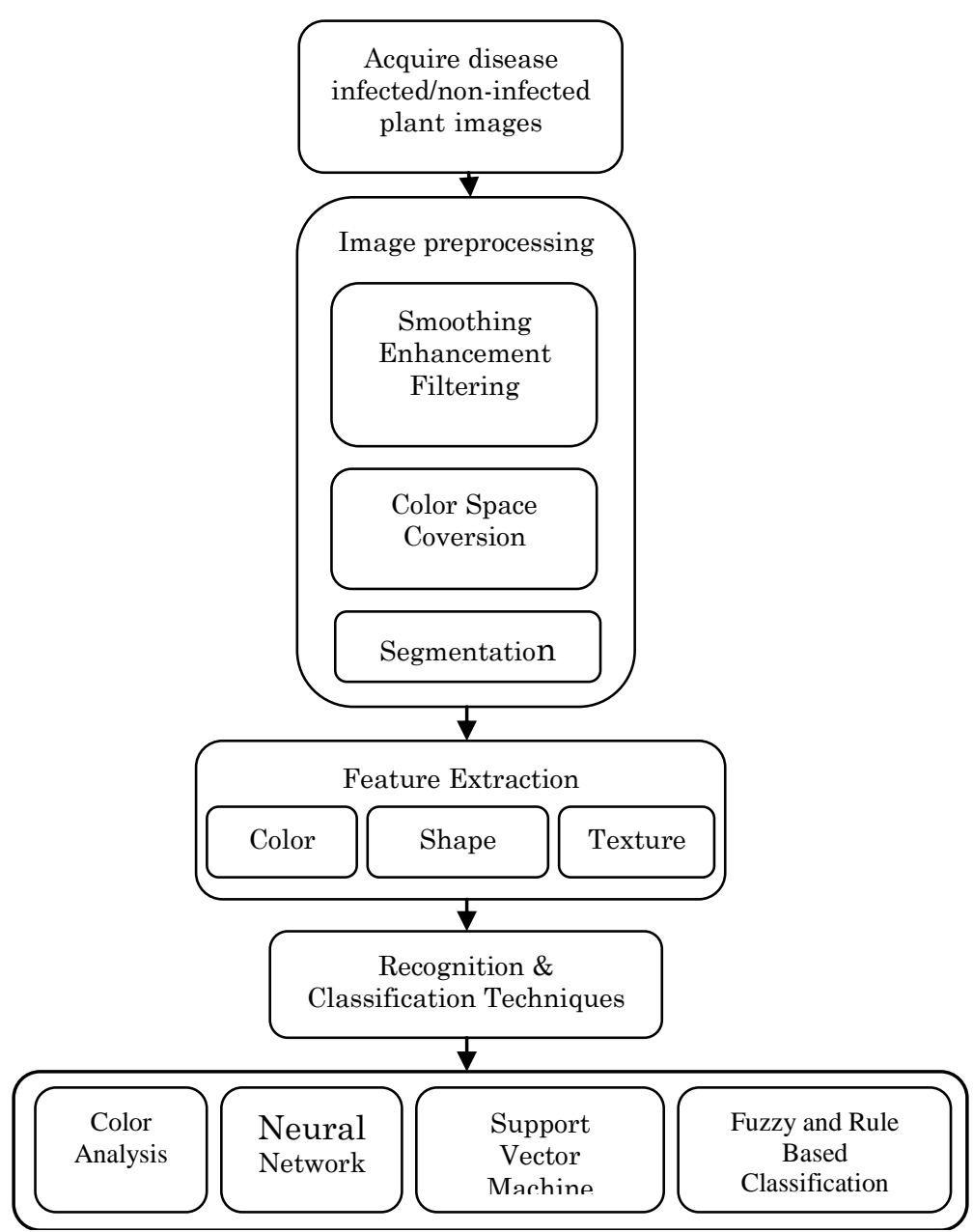

Figure 1. Steps used for plant disease recognition \& classification

The comparison and analysis of these four categories given in Table 5. A summary of various methods proposed by prominent authors given in Table 6.

\subsection{Plant Recognition and Classification Techniques}

\section{Feature Analysis}

[Pydipati et al. 2006] ${ }^{[25]}$ presented an approach for identifying a citrus disease by using machine vision techniques. In this study, the CCD camera and MV Tools software used for collecting disease infected citrus plant images under an artificial light generating setup using calibration gray card and controlled laboratory conditions. The four types of classes of citrus leaf samples collected: 1. Greasy Spot (Mycosphaerella citri), 2. Melanose (Diaporthe citri), 3. Scab (Elsinoe fawsettii) and 4. Normal citrus leaf. The color co-occurrence matrix (CCM) based texture analysis method developed to extract texture color features i.e. hue, saturation, and intensity (HSI) by using statistical classification. The algorithm was designed to detect infected and non-infected citrus leaves under controlled environmental conditions. The author has concluded that CCM texture feature achieved quite a good classification accuracy, for all four classes, using HSI color texture over intensity based analysis.

[Wiwart et al. 2009] ${ }^{[33]}$ applied digital color image analysis discrimination to detect four types of mineral deficiencies i.e. nitrogen, phosphorus, potassium, and magnesium. To conducting an experiment, the three types of legume species 
i.e. bean, pea and yellow lupine have used. The colored leaf images originally described in RGB model, and the values of these RGB components converted into HSI and L $\times a \times b$ color space. The deficiencies determined on the basis of the color difference between mineral deficiencies leaves or nondeficiencies leaves. The Euclidean distances were used to calculate the difference between the color spaces.

[Husin 2012$]^{[13]}$ designed a method to recognize the chili plant diseases. This algorithm contains the four steps that included first; the chili disease and healthy images captured using a digital camera and LABVIEW software. The total number of samples collected are 107 from which 21 are healthy, and 86 are disease affected samples. Second, the effect of illumination reduced by color space and separate chili and non-chili leaf color. Third, resulting pixels clustered according to the group of color pixels. Fourth, extract color features from color based segmentation performed on healthy and unhealthy chili leaf images. The authors reported satisfactory results of detection of chili leaf diseases, but the given description of the algorithm is not good.

[Zhang et al. 2010] ${ }^{[38]}$ aimed to recognize and classify lesions in citrus leaves. The proposed method first used the threshold for detection of citrus canker lesions for extracting global features. Second, to recognize another type of similar canker lesions used zone based local features extraction. A feature threshold and

weighted voting system used for final classification. An extension and more description of proposed a work given to authors next paper [Zhang et al. 2011] ${ }^{[39]}$. The author designed AdaBoost algorithm for classification with highest classification rate.

[Zhang et al. 2013] ${ }^{[40]}$ describes the method using orthogonal nonlinear discriminant projection (OLDP) for five kinds of maize plant disease recognition. The RGB images converted into HIS color space; mask and remove the green pixels; segment these components using thresholding technique. Transformation matrices are constructed from training data by using OLDP. The data so arranged is projected into lowdimensional feature space to predict the corresponding class label using the 1-nearest neighbor classifier. The performance of the proposed method (OLDP) evaluates and compare with three disease recognition methods. These methods are texture analysis (TA), neural networks based classification (NN) and eigenfeature regularization and extraction technique (ERET). The two manifold learning methods i.e. locality sensitive discriminant analysis LSDA and discriminant projection embedding (DPE). The three classifiers i.e. TA, NN, and ERET are designed to extract the disease classification features. The proposed a method (OLDP) designed to map the high-dimensionality leaf images to be low-subspace. The authors stated that as compared with LSDA and DPE, OLDP could yield the best classification performance on plant leaf classification.

[Opstad Kruse et al. 2014] ${ }^{[22]}$ proposed a pixel classification method for identification of leaf surface injury from digital images. The RGB images are captured under controlled laboratory conditions using a standard digital camera. The original RGB color space of images converted into $\mathrm{L} \times \mathrm{a} \times \mathrm{b}$ colored space, and the images unfolded in a specific manner into $2 \mathrm{D}$ feature matrix. The unfolding includes the neighbor of every pixel of interest to capture spatial information. The three supervised methods i.e. (1) Fit for a Pattern Multivariate Image Analysis approach combined with T2 (FPM-T2), (2) RSS statistics (FPM-RSS), and (3) linear discriminant analysis (LDA) used for pixel classification. The one unsupervised $k$-means clustering used for pixel classification. The authors reported that all three methods performed well in injured pixel identification except LDA.

Table 1. Feature Analysis Based Plant Disease Recognition and Classification

\begin{tabular}{|c|c|c|c|c|}
\hline References & $\begin{array}{c}\text { Disease/De- } \\
\text { ficiency/ Damage }\end{array}$ & $\begin{array}{l}\text { Environmental } \\
\text { Conditions (Required } \\
\text { or not for conducting } \\
\text { the experiment) }\end{array}$ & Applied Technique & $\begin{array}{l}\text { Recognition } \\
\text { and } \\
\text { Classification } \\
\text { Accuracy }\end{array}$ \\
\hline Pydipati et al. $\underline{2006}$ & Fungal & $\begin{array}{l}\text { Controlled Lighting } \\
\text { Conditions }\end{array}$ & Statistical Analysis & $95 \%$ \\
\hline Wiwart et al. $\underline{2009}$ & Deficiency & $\begin{array}{l}\text { Controlled environment } \\
\text { conditions }\end{array}$ & Euclidean Distances & - \\
\hline $\begin{array}{l}\text { Zhang et al. } \underline{2010} \\
\underline{2011}\end{array}$ & Bacterial & Images captured in field & $\begin{array}{l}\text { Thresholding and develop an } \\
\text { AdaBoost Algo. }\end{array}$ & $88 \%$ \\
\hline Husin $\underline{2012}$ & N/A & N/A & Color Analysis & $65 \%$ \\
\hline Zhang et al. $\underline{2013}$ & Fungal/Bacterial & N/A & LDA, DPE, and OLDP & $93 \%$ \\
\hline Molina et al. $\underline{2014}$ & Fungal & $\begin{array}{l}\text { Images captured under } \\
\text { greenhouse with } \\
\text { controlled temperature }\end{array}$ & Color Based Classification & $100 \%$ \\
\hline Wang et al. $\underline{2014}$ & Fungal & N/A & $\begin{array}{l}\text { Improved Rotational Kernel } \\
\text { Transformation Feature }\end{array}$ & $97.5 \%$ \\
\hline Opstad et al. $\underline{2014}$ & Damage & $\begin{array}{l}\text { Controlled Lighting } \\
\text { Conditions }\end{array}$ & $\begin{array}{l}\text { Fit to a Pattern MIA (FPM-T2), } \\
\text { RSS statistics [FPM-RSS], Linear } \\
\text { discriminant analysis [LDA], K- } \\
\text { means clustering }\end{array}$ & $\begin{array}{l}\text { LDA Classifier } \\
95 \%\end{array}$ \\
\hline
\end{tabular}


[Wang et at. 2014] $]^{[32]}$ proposed a technique for the recognition of wheat stripe rust and powdery mildew. The authors designed a new version of Rotational Kernel Transformation directional (IRKT) feature for disease recognition in the spatial domain. The captured images of infected and noninfected leaf areas converted the RGB space to HSV and YCbCr color spaces. Then, on the basis of color, the infected area separated from the background and the final segmentation performed using Otsu's method. The kernel based IRKT directional feature extracted from segmented areas, used to detect edges and achieved statistics directions of noise image. The results showed $97.5 \%$ recognition accuracy.

[Molina et al. 2014] ${ }^{[20]}$ presented the prototype for the detection of tomato early blight disease using the color-based classification. First, the annotated dataset created under greenhouse with specific temperature and the total number of images are 147 included 31 healthy and 28 infected with early blight. Second, total 190 (healthy 95 and early blight 95) ROI annotated characterization done by experts. Third, Color characterization of early blight based on three descriptors i.e. Color Structure Descriptor (CSD), Scalable Color Descriptor (SCD) and Color Layout Descriptor (CLD). Fourth, the nested leave one out used to compare the performance of three descriptors. The authors reported that the CSD showed better results as compared to SCD and CLD.

\section{Neural Network}

[Sanyal et al. 2007] ${ }^{[28]}$ described a prototype to diagnose six deficiencies in the rice crop using color texture analysis. Firstly, gray level co-occurrence matrix (GLCM) based texture and color features extracted separately from the rice leaves images. Each feature submitted to different multilayer perceptron (MLP) classifier trained with the back-propagation algorithms. The multilayer perceptron (MLP) texture classifier consists of 40 hidden layers, and MLP color classifier consists of 70 hidden layers. The authors predicted that the output of a combination of two MLP was final classification and satisfactory.

[Haung 2007] ${ }^{[12]}$ presented a method to detect and classify bacterial soft rot, bacterial brown spot, and Phytophthora black rot diseases of Phalaenopsis orchid seedling using the neural network and image processing techniques. The CCD color camera used for acquiring disease affected images and stored in tagged image file format (TIF). The segmentation procedure consists of four steps: First, the Bayes classifier applied to classify plant leaves and plant pot object from the background. Second, an exponential transformation performed the equalization of images. Third, a rough estimation used to locating disease regions in the images, and the last, centered position of the rough location performed the equalization of sub-images. The feature extraction carried texture and color features using gray level co-occurrence matrix (GLCM). These features submitted to back propagation neural network for final classification. The algorithm efficiently reached the classification of three types of Phalaenopsis orchid seedling diseases.

[Phadikar and Sil 2008] ${ }^{[23]}$ designed a method to detect and classify two rice crop diseases i.e. rice blast and brown spot. The disease image samples are captured by digital camera and then transformed to Hue Intensity Saturation (HIS) color space to perform entropy-based threshold for segmentation. The segmentation process used boundary detection algorithm based on 8-connectivity method [Gonzalez, 2008] ${ }^{[9]}$ and green components used for identifying disease spots from segmented images. These segmented spots normalized into $80 * 100$ size pixels, and finally these pixel values are fed into the self-organizing map (SOM) neural network for final classification.

[Al Bashish et al. 2010] $]^{[1]}$ proposed a framework to detect early scorch, cottony mold, ashen mold, late scorch, tiny whiteness diseases of the plant. The species of the plants not mentioned in the paper. After applying some preprocessing on images, images divided into clusters by using a $k$-means clustering algorithm. These clusters divided into further four types, and each cluster represents one kind of disease among five. Further, feature extraction process used color cooccurrence method for extracting color and texture features. The multi-layer perceptron (MLP) neural network (ten hidden layers) performed the classification.

[Kai et al. 2011] $]^{[15]}$ presented a technique for the identification of corn disease infected images. The image texture characteristics of corn diseases used as $\mathrm{YCbCr}$ color representation. A rule-based approach applied for segmenting infected spot to segment the unhealthy regions properly. The gray level co-occurrence matrix (GLCM) performed feature extraction from the unhealthy region of corn plant images. The extracted features from segmented regions submitted to multi-layer perceptron (MLP) neural network for final recognition.

[Wang et al. 2012a] ${ }^{[29]}$ aimed to classify four fungal diseases. Two diseases of wheat crop i.e. stripe rust, leaf rust and two of grape i.e.downey mildew, powdery mildew. The median filter applied to denoised images. After that, image segmentation performed using k-means clustering. The total 50 features extracted that are color 21 , shape 4 and texture 25 . The four classification techniques applied and tested: Multilayer Perceptron (MLP), Radial Basis Function (RBF), Generalized Regression, and Probabilistic for classification. The result stated that all kinds of neural networks achieved pleasant identification and classification, and quite fitting accuracy for each feature group. In his another work[Wang et al. 2012b] ${ }^{[30]}$, the feature extraction is done using the same technique proposed in their previous paper [Wang et al. $2012 \mathrm{a}]^{[29]}$. On the same dataset principal component analysis (PCA) applied to features summarization. The four classifiers i.e. back propagation (BP) networks, radial basis function (RBF)] neural networks, generalized regression networks (GRNNs) and probabilistic neural networks (PNNs) performed the final identification.

[Sannakki et al. 2013] ${ }^{[27]}$ proposed a procedure to diagnose downey mildew and powdery mildew disease found on grape plant leaves. Mean of threshold removed the background information of unhealthy images and followed by the segmentation process, which is performed by using $k$-mean clustering algorithm. The images divided into six clusters corresponding to lesions. The gray level co-occurrence matrix (GLCM) extracted features based on color texture from diseased regions. The color co-occurrence texture analysis method used spatial gray-level dependence matrices (SGDM's). The feed forward back propagation neural network (BPNN) classifier applied for final classification. The authors reported good validation results and showed the proper classification of two diseases. 
Table 2. Neural Network for Plant Disease Recognition and Classification

\begin{tabular}{|c|c|c|c|c|}
\hline References & $\begin{array}{l}\text { Disease } \\
\text { Type/Deficiency }\end{array}$ & $\begin{array}{l}\text { Environmental Conditions } \\
\text { (Required or not for } \\
\text { conducting the } \\
\text { experiment) }\end{array}$ & Applied Technique & $\begin{array}{l}\text { Recognition and } \\
\text { Classification } \\
\text { Accuracy }\end{array}$ \\
\hline Sanyal et al. $\underline{2007}$ & Deficiency & N/A & $\begin{array}{l}\text { BPNN and } \\
\text { MLP Classifier }\end{array}$ & $89.6 \%$ \\
\hline Haung $\underline{2007}$ & Bacterial & N/A & BPNN & $90.1 \%$ \\
\hline $\begin{array}{l}\text { Phadikar and Sil } \\
2008\end{array}$ & Fungal & Not Required & SOP & $\begin{array}{l}\text { Highest } \\
\text { classification 92\% }\end{array}$ \\
\hline $\begin{array}{l}\text { Al Bashish et al. } \\
2010\end{array}$ & $\begin{array}{l}\text { General } \\
\text { (Fungal/Bacterial) }\end{array}$ & N/A & BPNN & $96.6 \%$ \\
\hline Kai et al. $\underline{2011}$ & Fungal & N/A & BPNN & $98 \%$ \\
\hline $\begin{array}{l}\text { Wang et al. } \underline{2012 a} \\
\underline{2012 b}\end{array}$ & Fungal & N/A & $\begin{array}{l}\text { BPNN, RDF } \\
\text { NN, GRNN, and PNN }\end{array}$ & $91.4 \%$ and $94.2 \%$ \\
\hline Asfarian et al. $\underline{2013}$ & $\begin{array}{l}\text { Fungal/Bacterial/Vi } \\
\text { rus }\end{array}$ & N/A & PNN & $83 \%$ \\
\hline $\begin{array}{l}\text { Krishnan and } \\
\text { Sumithra } \underline{2013}\end{array}$ & Bacterial & N/A & K-mean Clustering & - \\
\hline Sannakki et al. $\underline{2013}$ & Fungal & Images captured in field & PCA and NN & $\begin{array}{l}\text { With hue features } \\
\text { classification } 100 \%\end{array}$ \\
\hline Wang et al. 2013 & Bacterial spores & N/A & BPNN & $63.6 \%$ \\
\hline
\end{tabular}

[Wang et al. 2013] $]^{[31]}$ designed an integrated intelligent device i.e. spore image sequence capture device for capturing powdery mildew spores. The algorithm begins with the preprocessing of captured images followed by Otsu's segmentation. The various features such as perimeter, area, roundness, shape complexity and four Hue invariant moments of connected domain extracted. Backpropagation network performs the final identification. The proposed method reported the good accuracy of identification of powdery mildew spores.

[Asfarian et al. 2013] ${ }^{[4]}$ proposed a method for identification of paddy diseases (leaf blast, brown spot, bacterial leaf blight, and Tungro) using texture analysis with fractal descriptors based on Fourier spectrum. The disease affected images extracted manually later converted into HIS color space from which the saturation components extracted. The histogram equalization performed for reducing the lighting effect. The images sharpened using a Laplacian filter. Finally, fractal descriptors are extracted from each lesion and then submitted to probabilistic neural networks (PNN) classifier for final classification. The author stated that the proposed fractal descriptor method had potential to identify paddy diseases.

[Krishnan and Sumithra 2013] $]^{[16]}$ stated that image processing technique can diagnose bacterial leaf scotch of shade tree species. The images of shade tree leaves are acquired, followed by clustering based segmentation. The kmeans clustering is used to separate cluster groups. The final clustering is performed by subtracting reference images from base images to form convoluted clusters from acquired images.

\section{Support Vector Machine}

[Meunkaewjinda et al. 2008] $]^{[19]}$ designed a system to diagnosis plant disease by using intelligent techniques to detect and classify diseases that affect grapevines. For extracting grape color features, $\mathrm{H}$ and $\mathrm{B}$ components from HSI and LAB color space is used to reduce the effect of illumination. For the extracting grape disease, color features, the three components i.e.

A, U and $\mathrm{Cr}$ from LAB, UVL, YCbCr color spaces are extracted. The resultant grape color pixels clustered by unsupervised self-organizing feature map (SOFM) network. The so obtained grouped pixel values separated from the background by using the back-propagation network. The modified self-organizing feature map (MSOFM) applied to resultant grape disease color pixels. To determines the different clusters for each case genetic algorithm (GA) applied, and next support vector machine SVM separated the affected and non-affected regions. Before final classification, some irrelevant pixels of grape disease segmented images are eliminated by using convolution and thresholding and subsequently applied Gabor filter to obtained disease appearance features. Finally, the classification of three different classes', i.e., scab, rust and no disease performed by using multiclass SVM.

[Youwen et al. 2008] ${ }^{[35]}$ discussed a method of recognizing powdery mildew and downey mildew diseases that affect cucumber leaves. To the removal of the noise from affected images, a median filter applied and then two approaches statistic pattern and mathematics morphology used to segment the images in healthy and unhealthy regions. The color, shape and texture features of cucumber disease spot color are an extract from images. At last, these features are fed to SVM and performed the classification. The authors stated that the recognition rates of cucumber disease achieved by combined features of shape and texture using SVM. The combined features using SVM results better as compared to a combination of shape and SVM only. The features give correct results. 
[Camargo et al. 2009b] ${ }^{[6]}$ proposed a method to recognize three cotton plant diseases i.e. southern green stink bug, bacterial angular and ascochyta blight. The algorithm first transformed the color space to HSV color space and I1I2I3 color. From these transformations, only $\mathrm{H}$ component and I3 modified components used for segmentation. The segmentation is done using a threshold based on the histogram of intensity [Prewitt $\underline{1970}]^{[24]}$ technique [Camargo and Smith 2009a $]^{[5]}$. Afterward, the extracted features supplied to two classifiers i.e. SVM and SVM with oneagainst-one method [Hsu et al. 2002$]^{[11]}$ to classify unhealthy regions.

[Yao et al. 2009] ${ }^{[36]}$ proposed an application to detect three rice diseases. It includes bacterial leaf blight, sheath blight, and blast. The CCD color camera captures the images, and then these images transformed from RGB color to y1 and y2 modes. Afterward, Otsu's method used to perform segmentation. Subsequently, feature extraction performed including color, shape, and texture and these features supplied to support vector machine for final classification.

[Zhang et al. 2010] ${ }^{[37]}$ describes the method to recognize cucumber disease using support vector machine. In this experiment, the samples of each spot of leaves have been taken rather than the samples of each cucumber leaf disease. The author used image clipping technology for wiping the noise to separate the disease's spots from the background and then used threshold for the final segmentation. The three features color, shape and texture retrieved from spot color images. These features are submit to four classifiers that are
Support Vector Machine (SVM) based on Radial Basis Function (RBF) kernel function, Polynomial Kernel Function (PKF) and Sigmoid Kernel Function (SKF). The authors stated that the RBF kernel function reported better results as compared to PKF and SKF kernel functions.

[Arivazhagan et al. 2013] ${ }^{[3]}$ proposed a system for automatic plant disease detection and classification. The method consists of

four steps, i.e., 1) color transformation from RGB to HSI color space, masking and removal of masked green pixels, 2) threshold-based segmentation, 3) extracted color and texture features, and 4) submitted to minimum distance criterion (MDC) and support vector machine (SVM). The output of the experiment shows that SVM classifier is resulting better than the MDC classifier.

\section{Fuzzy and Rule-based Classification}

[Anthonys and Wickramarachchi $\underline{2009}]^{[2]}$ presented a method for classification and recognition of rice blast, rice shealt blight and brown spot disease of paddy crops. The acquired color disease images are processed by using digitization. The threshold and mathematics morphologies used for segmentation. The features (color, shape, and texture) extracted from unhealthy images. For final classification, the predefined values were used to compare with extracted color disease features by Membership functions. The authors concluded that the identification of rice blast and brown spot images more successfully recognized than rice sheath blight.

Table 3. Support Vector Machine for Plant Disease Recognition and Classification

\begin{tabular}{|c|c|c|c|c|}
\hline References & $\begin{array}{c}\text { Type of } \\
\text { Disease/Deficienc } \\
\text { y/Damage }\end{array}$ & $\begin{array}{l}\text { Environmental Conditions } \\
\text { (Required or not for } \\
\text { conducting the experiment) }\end{array}$ & Applied Technique & $\begin{array}{l}\text { Recognition and } \\
\text { Classification } \\
\text { Accuracy }\end{array}$ \\
\hline $\begin{array}{l}\text { Meunkaewjinda et } \\
\text { al. } 2008\end{array}$ & N/A & N/A & $\begin{array}{l}\text { BPNN, MSOFM, GA } \\
\text { and SVM }\end{array}$ & $97.8 \%$ \\
\hline $\begin{array}{l}\text { Youwen et al. } \\
2008\end{array}$ & N/A & N/A & SVM & $\begin{array}{l}\text { Highest Recognition } \\
100 \%\end{array}$ \\
\hline $\begin{array}{l}\text { Camargo and } \\
\text { Smith } \underline{2009 a} \\
\underline{2009 b}\end{array}$ & Damages & N/A & $\begin{array}{l}\text { Thresholding and } \\
\text { SVM }\end{array}$ & $\begin{array}{l}\text { Average } \\
\text { classification above } \\
50 \%\end{array}$ \\
\hline $\begin{array}{l}\text { Anthonys and } \\
\text { Wickramarachchi } \\
\underline{2009}\end{array}$ & Fungal & $\begin{array}{l}\text { Controlled Lighting } \\
\text { Conditions }\end{array}$ & SVM & $\begin{array}{l}\text { Highest Recognition } \\
85 \%\end{array}$ \\
\hline Yao et al. $\underline{2009}$ & Fungal & $\begin{array}{l}\text { Images captured in Rice Field } \\
\text { from four different angles }\end{array}$ & SVM & $\begin{array}{l}\text { Classification } \\
\text { accuracy } 100 \% \\
\text { using four shape } \\
\text { features }\end{array}$ \\
\hline Zhang et al. $\underline{2010}$ & Fungal & N/A & SVM & $\begin{array}{l}\text { Highest Recognition } \\
91.7 \%\end{array}$ \\
\hline $\begin{array}{l}\text { Arivazhagan et al. } \\
2013\end{array}$ & Fungal & N/A & SVM & $94 \%$ \\
\hline
\end{tabular}

[Kurniawati et al. 2009a 2009b] ${ }^{[17][18]}$ tries to develop an application to diagnosis the three different kinds of diseases (blast, brown spot, and narrow brown spot) that affect paddy crops. The method adopted two kinds of the threshold (Otsu's and local entropy) for the segmentation purpose. Then, the features extraction is done by extracting color, shape, and texture features. The final classification is performed to discriminate according to the corresponding selected regions by using predefined set of rules.

[Hairuddin et al. 2011] ${ }^{[10]}$ proposed a method for recognition of seven types of deficiencies found in oil palm plants. The segmentation performed on deficiencies image dataset according to color similarities, but the author didn't mention the segmentation process. The two features (color and texture) 
are extracted. The extracted features fed to the fuzzy classifier as input and corresponding fertilizer as output. The fuzzy rules are design based on interviews with the expert personnel. The technical details of proposed method are not available in paper.

$[\mathrm{Xu} \text { et al. } 2011]^{[34]}$ described a technique to identify two deficiencies (nitrogen and potassium) in a tomato plant. The feature extraction process includes extraction of color features based on Lxaxb color space in which $b^{*}$ component considered only and texture feature extraction based on Difference Operators, Fourier transform, and Wavelet packet decomposition. The selected features extracted by a genetic algorithm to perform detection of nitrogen and potassium deficiencies. The final identification performed when the optimized feature combination fed to fuzzy K-nearest neighbor classifier.

[Zhou et al. 2013] ${ }^{[41]}$ proposed an algorithm to detect and classify rice hopper infection (RHP). The infected rice stem images acquired and then applied smoothing, denoising, color space transformation. After that, authors applied box-counting dimension algorithm for extracting eigenvalues. The final identification and classification are used Linear Regression Model (LDM) and Fuzzy C-means Clustering (FCM). The accuracy of differentiating RHP infected images or nonimages are quite satisfactory by using fractal eigenvalues.

[Oberti et al. 2014] ${ }^{[21]}$ tried to design an automatic sensitivity (unhealthy tissue) detection system. The experiment has total 35 grapevine leave samples collected including Training set:10 samples and Testing set:25 samples. The images acquired at different capturing angles i.e. 0 to 75 degrees for creating training and testing images to carry out sensing measurement of early-middle symptoms, rather than perpendicular to the leaf surface. The regions of interest extracted from training images for healthy tissues, powdery mildew affected tissues, and other pigmented tissues. The testing images used to test proposed technique. The

first step of a program disease algorithm is to perform segmentation by fitting Gaussian mixture to a histogram of NIR (Near Infrared) pixel intensities by the implementation of an 'expectation maximization' algorithm. Then, rule-based classification is applied to compare non-infected and disease affected tissues. The authors stated that delectability of sensitivity could improved under specific conditions and laboratory setup. Authors also suggested doing imaging an angle within the range of about 40-60 degrees.

Table 4. Fuzzy and Rule Based Technique for Plant Disease Recognition and Classification

\begin{tabular}{|c|c|c|c|c|}
\hline References & $\begin{array}{c}\text { Type of } \\
\text { Disease/Deficie } \\
\text { ncy }\end{array}$ & $\begin{array}{l}\text { Environmental Conditions } \\
\text { (Required or not for conducting } \\
\text { the experiment) }\end{array}$ & Applied Technique & $\begin{array}{c}\text { Recognition and } \\
\text { Classification Accuracy }\end{array}$ \\
\hline $\begin{array}{l}\text { Kurniawati et } \\
\text { al. } \underline{2009 a} \\
\underline{2009 b}\end{array}$ & Fungal & N/A & Production Rules & $94 \%$ \\
\hline $\begin{array}{l}\text { Hirudin et al. } \\
\underline{2011}\end{array}$ & Deficiency & $\begin{array}{l}\text { Images captured in Oil Palm } \\
\text { Field }\end{array}$ & Fuzzy Classifier & - \\
\hline Xu et al. $\underline{2011}$ & Deficiency & $\begin{array}{l}\text { Images captured with different } \\
\text { degrees of nutrient deficiencies }\end{array}$ & $\begin{array}{l}\text { Fuzzy K-Nearest } \\
\text { Neighbor Classifier }\end{array}$ & Deficient classification $90 \%$ \\
\hline $\begin{array}{l}\text { Zhou et al. } \\
\underline{2013}\end{array}$ & Infection & $\begin{array}{l}\text { Images captured at greenhouse } \\
\text { with natural temperature and } \\
\text { photoperiod conditions }\end{array}$ & Fuzzy C-means & $63.5 \%$ \\
\hline $\begin{array}{l}\text { Oberti et al. } \\
2014\end{array}$ & Fungal & Controlled Lighting Conditions & Rule-based Classifier & $72 \%$ \\
\hline
\end{tabular}

\section{COMPARISION AND}

\section{PERFORMANCE ANALYSIS}

The section describes the comparison and analysis of four categories. As shown in Table 5 that highest accuracy for plant disease recognition and classification done under three categories i.e Feature Analysis using color-based classification (Molina et al. 2014) ${ }^{[20]}$ with $100 \%$ accuracy, Neural Networks using PCA and NN (Sannakki et al. 2013) with $100 \%$ accuracy and Support Vector Machine (Yao et al. 2009) with $100 \%$ accuracy.

Table 5. Comparison and performance analysis of plant recognition and classification of four categories

\begin{tabular}{ccclc}
\multicolumn{2}{c}{ Table 5. Comparison and performance analysis of plant recognition and classification of four categories } \\
\hline Category & References & $\begin{array}{c}\text { Diseases/Damage/ } \\
\text { Deficiency }\end{array}$ & \multicolumn{1}{c}{$\begin{array}{c}\text { Applied Technique } \\
\text { Recognition and } \\
\text { Classification } \\
\text { Accuracy }\end{array}$} \\
\hline Feature Analysis & Molina et al. $\underline{\underline{2014}}$ & Fungal & Color Based Classification & $100 \%$ \\
& Wang et al. $\underline{2014}$ & Fungal & $\begin{array}{l}\text { Improved Rotational Kernel } \\
\text { Transformation Feature }\end{array}$ & $97.5 \%$
\end{tabular}

These techniques are accurately resulting in fungal diseases in the three cases for disease recognition. The various techniques applied for the classification and their recognition accuracy summarized as per category in Table $\underline{1}, \underline{2}, \underline{3}$ and $\underline{4}$. The tables carried the description of technique applied, their recognition accuracy, and environment conditions required for the execution of the experiment and on the type of disease the experiment executed by the referred papers. 


\begin{tabular}{|c|c|c|c|c|}
\hline & Opstad et al. $\underline{2014}$ & Damage & Linear discriminant analysis [LDA] & $95 \%$ \\
\hline \multirow[t]{3}{*}{$\begin{array}{l}\text { Neural } \\
\text { Networks }\end{array}$} & $\begin{array}{l}\text { Sannakki et al. } \\
\underline{2013}\end{array}$ & Fungal & $\begin{array}{l}\text { Principle Component Analysis and } \\
\text { Neural Network }\end{array}$ & $100 \%$ \\
\hline & Kai et al. $\underline{2011}$ & Fungal & Back Propagation Neural Network & $98 \%$ \\
\hline & $\begin{array}{l}\text { Al Bashish et al. } \\
\underline{2010}\end{array}$ & $\begin{array}{l}\text { General } \\
\text { (Fungal/Bacterial) }\end{array}$ & Back Propagation Neural Network & $96.6 \%$ \\
\hline \multirow[t]{3}{*}{$\begin{array}{l}\text { Support Vector } \\
\text { Machine }\end{array}$} & Yao et al. $\underline{2009}$ & Fungal & $\begin{array}{l}\text { Support Vector Machine(Extracting } \\
\text { Shape Feature) }\end{array}$ & $100 \%$ \\
\hline & $\begin{array}{l}\text { Youwen et al. } \\
\underline{2008}\end{array}$ & N/A & Support Vector Machine & $100 \%$ \\
\hline & $\begin{array}{l}\text { Meunkaewjinda et } \\
\text { al. } 2008\end{array}$ & N/A & Support Vector Machine & $97.8 \%$ \\
\hline \multirow{2}{*}{$\begin{array}{l}\text { Fuzzy and Rule } \\
\text { Based } \\
\text { Technique }\end{array}$} & $\begin{array}{l}\text { Kurniawati et al. } \\
\underline{2009 \text { a } 2009 \mathrm{~b}}\end{array}$ & Fungal & Production RuleBased Classification & $94 \%$ \\
\hline & Xu et al. $\underline{2011}$ & Deficiency & Fuzzy K-Nearest Neighbor Classifier & $90 \%$ \\
\hline
\end{tabular}

\section{DISCUSSION AND SUMMARIZATION}

An overview of all presented papers in this paper given in Table 6. The comprehensive details of diseases from which plant is affected, a device used for acquiring images from infected plant and techniques used for solving the problem presented. The summary of this study is as follows:

- The subject of plant disease detection and classification using image processing is undergoing from last 25 and more years. However, the study used fewer numbers of methods, or few methods are more used. For example, Support Vector Machine (Yao et al. 2009 $9^{[36]}$, Youwen et al. $2008^{[35]}$ etc.), Back Propagation neural networks (Kai et al. $2011^{[15]}$, Al Bashish et al. 2010 ${ }^{[1]}$, etc ). Therefore, more sophisticated methods (genetic algorithm, decision tree, and some more clustering) can be used for the concerned problem.

- Environmental conditions are another kind of constraint for collecting the images in controlled laboratory conditions (Pydipati et al. 2006 ${ }^{[25]}$, Oberti et al. 2014 ${ }^{[21]}$, etc.) different capturing angles (Xu et al. 2011 ${ }^{[34]}$ ) and particular size while capturing, high resolution capturing devices and precise length required. These conditions somehow make the task more complex and time-consuming. There is a need to relax the conditions while collecting the images.

- Plant species and different type of diseases used in the research are also specific. As most of the research, work is going on paddy crops and fungal/bacterial (Molina et al. 2014 ${ }^{[20]}$, Al Bashish et al. $2010^{[1]}$, etc.) diseases of plants. However, more plant species and more diseases (fungal, bacterial, viral and more deficiencies) can also be considered to enhance the research area.

- The presentation of the proposed method was less streamlined (Wang et al. 2012 $\mathrm{a}^{[29]} 2012 \mathrm{~b}^{[30]}$, Husin $2012^{[13]}$, etc.). In some cases, authors missed to attaining useful and required technical information. In other some cases, even missed giving the adequate description of proposed method that may understand by only those who have sufficient knowledge in the context.
- Lack of systematic study (Husin 2012 $2^{[13]}$, Arivazhagan et al. $2013^{[3]}$, etc.). In many cases, the problem demands the most technical knowledge to use more sophisticated technical tools in a systematic manner.

\section{CONCLUSION AND FUTURE HORIZONS}

In the subject of automatic identification and classification of pathologies, there are huge ranges of techniques and applications found in the literature using digital imaging. It's difficult to retrieve all ideas to presents in the paper that have many potential solutions for the issues not raised. The plant disease detection and recognition using image processing techniques is a wide area of research and concentrating only plant detection through digital images is the sub-area of the research. The sub-area itself has a wide scope of future research to automate the process of plant disease recognition. Some of the future aspects are following which can help the researchers working in the same field of research

- The research area is not limited to detection and recognition of the disease from which the plant is suffering but also detects the various stages of the particular disease and can provide various solutions to the problem at that very stage.

- Quantification or severity of disease is another wide area of research that how much the plant is affected by the disease in terms of quantification.

- Plant disease prediction and forecasting are also the area of related research.

- The mobile based application can be designed by using an automate plant disease identification and classification techniques that will help field farmers for providing instant solutions.

- The web portals can design for giving accurate online solutions related to plant diseases.

- These techniques can also help in designing plant disease recognition based on remote sensing images. 
The plant detection and recognition area of a research area are not limit to above-mentioned future scope. There are more other many areas that are still may not include, but researchers have to explore more.

In this review, as there are so many methods are proposed and implemented to identify and classify plant diseases using digital imaging and soft computing techniques. The paper presents an overview of technical concepts used in the methods existing in the literature related to the objective of the paper. Although, it is more important to underline and highlight the solution provided by the papers. Thus, if readers required more information about the methods mentioned, they could refer the cited articles respectively.

Table 6: Summarization of studies on plant disease recognition and classification using image processing and soft computing techniques.

\begin{tabular}{|c|c|c|c|c|}
\hline Plant & Disease/Damage/Deficiency & $\begin{array}{l}\text { Device used for Image } \\
\text { Acquisition }\end{array}$ & $\begin{array}{l}\text { Tool used for } \\
\text { Recognition \& } \\
\text { Classification }\end{array}$ & References \\
\hline Citrus & $\begin{array}{l}\text { Greasy spot (Mycosphaerella } \\
\text { citri), melanose (Diaporthe } \\
\text { citri), scab (Elsinoe fawsettii) }\end{array}$ & $\begin{array}{l}3 \text { CCD Camera [JAI, } \\
\text { MV90] }\end{array}$ & Statistical analysis & Pydipati et al. $\underline{2006}$ \\
\hline Rice & $\begin{array}{l}\text { Deficiency of Boron, Iron, } \\
\text { Magnesium, Manganese, } \\
\text { Nitogen, Potassium }\end{array}$ & $\begin{array}{l}\text { Camera attached to } \\
\text { mobile device }\end{array}$ & $\begin{array}{l}\text { Back propagation and } \\
\text { MLP Classifier }\end{array}$ & Sanyal et al. $\underline{2007}$ \\
\hline Phalaenopsis & $\begin{array}{l}\text { Bacterial soft rot (BSR), } \\
\text { bacterial brown spot (BBS), } \\
\text { and Phytophthora black rot } \\
\text { (PBR). }\end{array}$ & $\begin{array}{l}\text { CCD (Coupled-Charge } \\
\text { Device) color camera } \\
\text { (XC-711, Sony, Japan) }\end{array}$ & $\begin{array}{l}\text { Back Propagation Neural } \\
\text { Network }\end{array}$ & Haung $\underline{2007}$ \\
\hline Rice & Blast and Brown spots & $\begin{array}{l}\text { Nikon COOLPIX } \\
\text { P4 digital camera }\end{array}$ & Self-Organizing Maps & Phadikar and Sil $\underline{2008}$ \\
\hline Grape & N/A & N/A & $\begin{array}{l}\text { BPNN, MSOFM, GA and } \\
\text { Support Vector Machine }\end{array}$ & $\begin{array}{l}\text { Meunkaewjinda et al. } \\
2008\end{array}$ \\
\hline Cucumber & N/A & N/A & Support Vector Machine & Youwen et al. $\underline{2008}$ \\
\hline Cotton & $\begin{array}{l}\text { Green stink bug (Nezara } \\
\text { viridula]; Bacterial angular } \\
\text { (Xanthomonascampestris); } \\
\text { Ascochyta blight (Ascochyta } \\
\text { gossypii) }\end{array}$ & N/A & $\begin{array}{l}\text { Thresholding and } \\
\text { SVM }\end{array}$ & $\begin{array}{l}\text { Camargo and Smith } \underline{2009 a} \\
\underline{2009 b}\end{array}$ \\
\hline Rice & Spots & $\begin{array}{l}\text { CCD color camera } \\
\text { (Nikon D80) }\end{array}$ & SVM & $\begin{array}{l}\text { Anthonys and } \\
\text { Wickramarachchi } \underline{2009}\end{array}$ \\
\hline $\begin{array}{l}\text { Faba bean, } \\
\text { pea, and } \\
\text { yellow } \\
\text { lupine }\end{array}$ & $\begin{array}{l}\text { Nitrogen, phosphorus, } \\
\text { potassium and magnesium }\end{array}$ & $\begin{array}{l}\text { NIKON Coolpix } 5000 \\
\text { Digital } \\
\text { Camera }\end{array}$ & Euclidean distances & Wiwart et al. $\underline{2009}$ \\
\hline Rice & $\begin{array}{l}\text { Blast } \\
\text { Disease, Brown-Spot Disease } \\
\text { and Narrow Brown- } \\
\text { Spot Disease }\end{array}$ & $\begin{array}{l}\text { Canon Powershot G2 } \\
\text { digital camera }\end{array}$ & Production Rules & $\begin{array}{l}\text { Kurniawati et al. } \underline{2009 a} \\
\underline{2009 b}\end{array}$ \\
\hline Rice & Rice spot & $\begin{array}{l}\text { CCD color camera } \\
\text { (Nikon D80) }\end{array}$ & SVM & Yao et al. $\underline{2009}$ \\
\hline Cucumber & N/A & N/A & $\begin{array}{l}\text { Radial Basis Function, } \\
\text { Polynomial and Sigmoid } \\
\text { kernel function based SVM }\end{array}$ & Zhang et al. $\underline{2010}$ \\
\hline N/A & $\begin{array}{l}\text { Early scorch, Cottony mold, } \\
\text { ashen mold, late scorch, } \\
\text { Tiny whiteness. }\end{array}$ & N/A & BPNN & Al Bashish et al. $\underline{2010}$ \\
\hline Citrus & Canker & N/A & $\begin{array}{l}\text { Thresholding and develop } \\
\text { an AdaBoost Algo. }\end{array}$ & Zhang et al. $\underline{2010} \underline{2011}$ \\
\hline $\begin{array}{l}\text { Oil Palm } \\
\text { Plant }\end{array}$ & Nutrient deficiencies & $\begin{array}{l}\text { Camera Lumix-LX5 } \\
\text { Panasonic }\end{array}$ & Fuzzy classifier & Hirudin et al. $\underline{2011}$ \\
\hline
\end{tabular}




\begin{tabular}{|c|c|c|c|c|}
\hline Tomatoes & $\begin{array}{l}\text { Nitrogen or } \\
\text { Potassium. }\end{array}$ & $\begin{array}{l}\text { PUNIX TMC-7DSP } \\
\text { Color digital camera }\end{array}$ & $\begin{array}{l}\text { Fuzzy K-nearest neighbor } \\
\text { classifier }\end{array}$ & $\mathrm{Xu}$ et al. $\underline{2011}$ \\
\hline Corn & Leaf Spot & N/A & BPNN & Kai et al. $\underline{2011}$ \\
\hline Wheat & Stripe rust and leaf rust & $\begin{array}{l}\text { Common Digital } \\
\text { Camera }\end{array}$ & $\begin{array}{l}\text { BPNN, RDF } \\
\text { NN, GRNN, and PNN }\end{array}$ & Wang et al. 2012a $\underline{2012 b}$ \\
\hline Chili & N/A & $\begin{array}{l}\text { Digital Camera and } \\
\text { Webcam using } \\
\text { LabVIEW Software }\end{array}$ & Color Analysis & Husin $\underline{2012}$ \\
\hline Wheat & Stripe rust and leaf rust & $\begin{array}{l}\text { Common Digital } \\
\text { Camera }\end{array}$ & PCA and NN & Sannakki et al. $\underline{2013}$ \\
\hline Maize & Disease spots & N/A & LDA, DPE, and OLDP & Zhang et al. $\underline{2013}$ \\
\hline $\begin{array}{l}\text { Rose, bean, } \\
\text { lemon and } \\
\text { banana } \\
\text { leaves }\end{array}$ & $\begin{array}{l}\text { Early scorch, } \\
\text { Yellow spots, brown spots } \\
\text { and late scorch. }\end{array}$ & $\begin{array}{l}\text { Common Digital } \\
\text { Camera }\end{array}$ & SVM & Arivazhagan et al. $\underline{2013}$ \\
\hline Rice & $\begin{array}{l}\text { Leaf blast, brown spot, } \\
\text { bacterial leaf blight, and } \\
\text { Tungro }\end{array}$ & N/A & $\begin{array}{l}\text { Probabilistic neural } \\
\text { networks }\end{array}$ & Asfarian et al. $\underline{2013}$ \\
\hline N/A & Bacterial leaf scorch & N/A & K-mean clustering & $\begin{array}{l}\text { Krishnan and Sumithra } \\
\underline{2013}\end{array}$ \\
\hline N/A & Powdery mildew spore & $\begin{array}{l}\text { Integration of intelligent } \\
\text { spores capture device }\end{array}$ & BP neural network & Wang et al. $\underline{2013}$ \\
\hline Rice & Hopper Infection & Canon SX110 IS & Fuzzy C-means & Zhou et al. $\underline{2013}$ \\
\hline Tomato & Early Blight & $\begin{array}{l}\text { CCD color camera and } \\
\text { Annotation Tool }\end{array}$ & Color Based Classification & Molina et al. $\underline{2014}$ \\
\hline Wheat & $\begin{array}{l}\text { Stripe Rust and Powdery } \\
\text { mildew }\end{array}$ & N/A & $\begin{array}{l}\text { Improved Rotational Kernel } \\
\text { Transformation Feature }\end{array}$ & Wang et al. $\underline{2014}$ \\
\hline Grapevine & Powdery mildew & $\begin{array}{l}\text { Multi-spectral camera } \\
\text { (MS4100) }\end{array}$ & Rule-based Classifier & Oberti et al. $\underline{2014}$ \\
\hline $\begin{array}{l}\text { Clover } \\
\text { leaves }\end{array}$ & Leaf surface injury & $\begin{array}{l}\text { Standard digital SLR } \\
\text { camera }\end{array}$ & $\begin{array}{l}\text { Fit to a Pattern MIA (FPM- } \\
\text { T2), RSS statistics [FPM- } \\
\text { RSS], Linear discriminant } \\
\text { analysis [LDA], K-means } \\
\text { clustering }\end{array}$ & Opstad et al. 2014 \\
\hline
\end{tabular}

\section{REFERENCES}

[1] Al Bashish D, Braik M, Bani-Ahmad S. 2010. A framework for detection and classification of plant leaf and stem diseases. In proceeding of 2010 International conference on signal and image processing. IEEE, Chennai, 113-118. DOI: 10.1109/ICSIP.2010.5697452.

[2] Anthonys G, Wickramarachchi N. 2009. An image recognition system for crop disease identification of paddy fields in Sri Lanka. In Proceeding of 2009 International Conference on Industrial and Information Systems (ICIIS). IEEE, Sri Lanka, 403-407. DOI:10.1109/ICIINFS.2009.5429828.

[3] Arivazhagan S, Shebiah R.N, Ananthi S, Varthini SV. 2013. Detection of unhealthy region of plant leaves and classification of plant leaf diseases using texture features. Agric Eng Int: CIGR Journal Vol. 15(1), 211-217.

[4] Asfarian A, Herdiyeni Y, Rauf A, Mutaqin KM. 2013. Paddy Diseases Identification with Texture Analysis

using Fractal Descriptors Based on Fourier Spectrum. In proceeding of International Conference on Computer, Control, Informatics and Its Applications. IEEE, Jakarta, 77-81, DOI: 10.1109/IC3INA.2013.6819152.

[5] Camargo A, Smith JS. 2009a. An image-processing based algorithm to automatically identify plant disease visual symptoms. Biosyst Eng 102(1), 9-21. DOI: 10.1016/j.biosystemseng.2008.09.030.

[6] Camargo A, Smith JS. 2009b. Image pattern classification for the identification of disease causing agents in plants. Comput Electron Agric, Vol. 66(2009), 121-125. DOI:10.1016/j.compag.2009.01.003.

[7] Du CJ, Sun DW. 2004. Recent developments in the applications of image processing techniques for food quality evaluation. Trends in Food Science \& Technology, Vol 15(2014), 230-249. DOI: 10.1016/j.tifs.2003.10.006. 
[8] Garcia J, Barbedo A. 2013. Digital image processing techniques for detecting, quantifying and classifying plant diseases. Barbedo: SpringerPlus 2013, Vol 2:660. DOI:10.1186/2193-1801-2-660.

[9] Gonzalez and Woods. 2008. The title of book( $3^{\text {rd }}$ Ed.) Digital Image Processing, Prentice-Hall, New Jersey.

[10] Hairuddin MA, Tahir NM, Baki SRS. 2011. Overview of image processing approach for nutrient deficiencies detection in Elaeis Guineensis. In proceeding of 2011 IEEE International Conference on system engineering and technology, IEEE, Shah Alam, 16120. DOI:10.1109/ICSEngT.2011.5993432.

[11] Hsu CW, Lin CJ .2002. A comparison of methods for multi-class support vector machines. IEEE Trans Neural Netw, Vol. 13, 415-425. DOI:10.1109/72.991427.

[12] Huang KY. 2007. Application of artificial neural network for detecting Phalaenopsis seedling diseases using color and texture features, Comput Electron Agric Vol. 57, 311. DOI:10.1016/j.compag.2007.01.015.

[13] Husin ZB, Abdul Aziz A. HB, Md Shakaff A. YB, Mohamed Farook R. YS. 2012. Feasibility Study on Plant Chili Disease Detection Using Image Processing Techniques. In proceeding of 2012 Third International Conference on IntelligentSystem Modelling and Simulation. IEEE, Kota Kinabalu, 291-296. DOI:10.1109/ISMS.2012.33.

[14] Jasmin G.D. and Rajan E.G. 2013. Normalized Vector Codes for Object Recognition using Artificial Neural Networks in the Framework of Picture Description Languages, Global Journal of Computer Science and Technology Neural \& Artificial Intelligence, Vol. 13 (2), Global Journals Inc. (USA) 25-33.

[15] Kai S, Zhikun L, Hang S, Chunhong G. 2011. A research of maize disease image recognition of corn based on BP networks. In proceeding of 2011 third international conference on measuring technology and mechatronics automation. IEEE, Shanghai, 246249. DOI:10.1109/ICMTMA.2011.66.

[16] Krishnan M, Sumrithra MG. 2013. A Novel Algorithm for Detecting Bacterial Leaf Scorch (BLS) of Shade Trees Using Image Processing. In proceeding of IEEE 11th Malaysia International Conference on Communications. IEEE, Kuala Lumpur, 474-478. DOI:10.1109/MICC.2013.6805876.

[17] Kurniawati NN, Abdullah SNHS, Abdullah S, Abdullah S. 2009a. Investigation on image processing techniques for diagnosing paddy diseases. In proceeding of 2009 International conference on soft computing and pattern recognition. IEEE, Malacca, 272-277. DOI: 10.1109/SoCPaR.2009.62.

[18] Kurniawati NN, Abdullah SNHS, Abdullah S, Abdullah S .2009b. Texture analysis for diagnosing paddy disease. In proceeding of 2009 International conference on electrical engineering and informatics. IEEE, Selangor, 23-27. DOI: 10.1109/ICEEI.2009.5254824.

[19] Meunkaewjinda A, Kumsawat P, Attakitmongcol K, Srikaew A .2008. Grape leaf disease detection from color imagery using hybrid intelligent system. In proceeding of 2008 5th international conference on electrical engineering/electronics, computer, telecommunications and information technology, IEEE, Krabi, 513-516. DOI:10.1109/ECTICON.2008.4600483.

[20] Molina JF, Gil R, Bojacá C, Gómez F, and Franco H. 2014. Automatic Detection of Early Blight on tomato Crops using a Colo Based Classification Strategy. In proceeding of 2014 19th International Symposium on Image, signal processing and Artificial Vision, IEEE, Armenia, 1-5. DOI:10.1109/STSIVA.2014.7010166.

[21] Oberti R, Marchi M, Tirelli P, Calcante A, Iriti M, Borghese A.N. 2014. Automatic detection of powdery mildew on grapevine leaves by image analysis: Optimal view-angle range to increase the sensitivity. Comput Electron Agric 104(2014), 1-8. DOI:http://dx.DOI.org/10.1016/j.compag.2014.03.001.

[22] Opstad Kruse OM, Prats-Montalbán JM, Indahl UG, Kvaal K, Ferrer A, Futsaether CM .2014. Pixel classification methods for identifying and quantifying leaf surface injury from digital images. Comput Electron Agric Vol. 108(2014), 155-165. DOI:http://dx.DOI.org/10.1016/j.compag.2014.07.010.

[23] Phadikar S, Sil J. 2008. Rice disease identification using pattern recognition techniques. In proceedings of 11th International Conference on Computer and Information Technology (ICCIT 2008), IEEE, Khulna, 420-423. DOI: 10.1109/ICCITECHN.2008.4803079.

[24] Prewitt J .1970. Object enhancement and extraction, Picture processing and psychopictorics, Academic Press, Orlando.

[25] Pydipati R, Burks TF, Lee WS. 2006. Identification of citrus disease using color texture features and discriminant analysis. Comput Electron Agric 52(2006), 49-59. DOI:10.1016/j.compag.2006.01.004.

[26] Sankaran S, Mishra A, Ehsani R, Davis C. 2010. A review of advanced techniques for detecting plant diseases. Comput Electron Agric Vol.72, 1-13. DOI:10.1016/j.compag.2010.02.007.

[27] Sannakki SS, Rajpurohit VS, Nargund VB, Kulkarni P. 2013. Diagnosis and Classification of Grape Leaf Diseases using Neural Networks, In proceeding of 4th International Conference (ICCCNT), IEEE, Tiruchengode, 1-5. 10.1109/ICCCNT.2013.6726616.

[28] Sanyal P, Bhattacharya U, Parui SK, Bandyopadhyay SK, Patel S. 2007. Color texture analysis of rice leaves diagnosing deficiency in the balance of mineral levels towards improvement of crop productivity. In proceeding of 10th International Conference on Information Technology (ICIT 2007), IEEE, Orissa, 8590. DOI: 10.1109/ICIT.2007.40.

[29] Wang H, Li G, Ma Z, Li X. 2012a. Application of neural networks to image recognition of plant diseases. In Proceedings of the 2012 International Conference on Systems and Informatics (ICSAI), IEEE, Yantai, 21592164. DOI: 10.1109/ICSAI.2012.6223479.

[30] Wang H, Li G, Ma Z, Li X. 2012b. Image recognition of plant disease based on principal component analysis and neural networks. In Proceedings of the 2012 8th International Conference on Natural Computation (ICNC 2012), IEEE, Chongqing, 246-252. DOI: 10.1109/ICNC.2012.6234701. 
[31] Wang D, Wang B, Y Yan. 2013. The identification of powdery mildew spores image based on the integration of intelligent spore image sequence capture device. In proceeding of Ninth International Conference on Intelligent Information Hiding and Multimedia Signal Processing, IEEE, Beijing, 170-180. DOI: 10.1109/IIHMSP.2013.53.

[32] Wang L, Dong F, Guo Q, Nie C, Sun S. 2014. Improved Rotational Kernel Transformation Directional Feature for Recognition of Wheat Stripe Rust and Powdery Mildew. In proceeding of Seventh International Conference on Image and Signal Processing, IEEE, Dalian, 286-291. DOI: 10.1109/CISP.2014.7003793.

[33] Wiwart M, Fordonski G, Zuk-Golaszewska K, Suchowilska E. 2010. Early diagnostics of macronutrient deficiencies in three legume species by color image analysis. Comput Electron Agric 65(2010), 125-132. DOI:10.1016/j.compag.2010.06.009.

[34] Xu G, Zhang F, Shah SG, Ye Y, Mao H. 2011. Use of leaf color images to identify nitrogen and potassium deficient tomatoes. Pattern Recognit Lett Vol. 32(2011), 1584-1590. DOI:10.1016/j.patrec.2011.04.020.

[35] Youwen T, Tianlai L, Yan N. 2008. The recognition of cucumber disease based on image processing and support vector machine. In proceeding of 2008 Congress on image and signal processing, IEEE, Sanya, 262-267. DOI: 10.1109/CISP.2008.29.

[36] Yao Q, Guan Z, Zhou Y, Tang J, Hu Y, Yang B. 2009. Application of support vector machine for detecting rice diseases using shape and color texture features. In proceeding of 2009 International conference on engineering computation, IEEE, Hong Kong, 79-83. DOI: 10.1109/ICEC.2009.73.

[37] Zhang J, Zang W. 2010. Support Vector Machine For Recognition Of Cucumber Leaf Diseases, In Proceeding of 2 nd International Conference on Advanced Computer Control (ICACC), IEEE, Shenyang, 590-594. DOI: 10.1109/ICACC.2010.5487242.

[38] Zhang M. 2010. Citrus canker detection based on leaf images analysis, In proceeding of 2 nd International Conference on information science and engineering, IEEE, Hangzhou, 3584-3587. DOI: 10.1109/ICISE.2010.5691630.

[39] Zhang M, Meng Q. 2011. Automatic citrus canker detection from leaf images captured in field. Pattern Recognit Lett, Vol. 32(15), 2036-2046. DOI:10.1016/j.patrec.2011.08.003.

[40] Zhang S, Zhang C. 2013. Orthogonal locally discriminant projection for classification of plant leaf diseases. In proceeding of Ninth International Conference on Computational Intelligence and Security. IEEE, Leshan, 241-245. DOI: 10.1109/CIS.2013.57.

[41] Zhuo Z, Zang Y, Li Y, Zhang Y, Wang P, Luo X. 2013. Rice plant-hopper infestation detection and classification algorithms based on fractal dimension values and fuzzy C-means. Mathematical and Computer Modelling 58(2013), 701-709. DOI:10.1016/j.mcm.2011.10.028. 